\title{
Immigration Policy with Partisan Parties
}

\author{
Humberto Llavador*and Angel Solano-García ${ }^{\dagger}$
}

August 12, 2009

\begin{abstract}
This paper analyzes the political economy of immigration when the salient electoral issue is the level of immigrants and the relevant immigration policy is the expenditure in immigration control. We consider that immigration affects voters' welfare through economic and non economic factors. We model political competition à la Wittman with the ideology of parties endogenously determined at equilibrium. Numerical simulations provide the levels of immigration proposed by the two parties and the composition of parties' constituencies. At equilibrium, parties propose different levels of immigration, located to the left and to the right of the median voter's ideal point. We find that improvements in the efficacy of immigration control increases the probability of victory of the party proposing a tighter immigration policy and decreases the disparity in parties' policy proposals.
\end{abstract}

Keywords immigration, ideological parties, unskilled and skilled labor. JEL Classification J61, F22, D72

*Departament d'Economia i Empresa. Universitat Pompeu Fabra and Barcelona GSE. Email: humberto.llavador@upf.edu

${ }^{\dagger}$ Department of Economic Theory and Economic History. Universidad de Granada. Spain. Email: asolano@ugr.es 


\section{Introduction}

The control of immigration is becoming a more and more relevant issue in the political debate of most developed countries. Examples such as the increase in government expenditure on the Mexico-US border enforcement, or the concept of an integrated and comprehensive "border strategy" for the EU (presented by the president of European Commission) reveal the increased support for strengthening the control of external borders.

This paper analyzes the political economy of immigration when the relevant electoral issue is the control of immigration and the relevant immigration policy is the expenditure in border control. For that purpose, we consider a politico-economic model with two partisan parties, whose ideologies are endogenously determined at equilibrium.

Many recent empirical studies, such as Bauer et al. (2000), Mayda (2006), or Dustmann and Preston (2005), have found that natives' attitudes towards immigrants are motivated by economic and non-economic factors, and in this paper we consider both. Among the economic effects of immigration, we focus on the impact of immigration on domestic labor market conditions, as it has been widely analyzed by empirical and theoretical papers (see Borjas et al. 1996, 1997). Two theoretical models are commonly used: the HeckscherOlin trade model and the factor-proportion analysis model (see Scheve and Slaugther (2001) for a descriptive summary of both models). These two models differentiate low skilled from high skilled workers as production factors. In both models, the competitive labor market implies that an increase in the relative less skilled labor supply increases the skill premium, increasing inequality in earnings between skilled and less-skilled workers. Following these approaches, we allow natives to be either skilled or unskilled workers. The two different types of labor are the unique production factors, and they are complementaries. Immigrants are considered unskilled workers, so that an increase in the number of immigrants reduces unskilled wage but increases skilled wage. About the non-economic factors we follow the evidence that less skilled workers tend to be less pro-immigration because of non-economic reasons (Dustmann and Preston 2005, Mayda 2006).

With respect to the political process we consider the Endogenous Party Wittman Equilibrium (EPWE), an extension of the Wittman Equilibrium proposed by Roemer (2001). Two ideological parties compete in an election by proposing two immigration policies. Voters vote sincerely for their preferred policy and the party with the highest share of the vote wins the election and implements the announced policy. The ideology of each party is endogenously determined by aggregating the preferences of its voters.

Three papers have studied a political competition model with an EPWE: 
Ortuño-Ortín and Roemer (1998), who investigate the classical political economy of financing a public good; De Donder and Hindriks (2006), who focus on the political economy of social insurance programs; and Lee and Roemer (2005), who analyze the changes in coalition formation between workers of different skills who have to choose the structure of the labor market (to be more or less unionized). Our analysis is closer to the latter because both papers consider workers with different skills, but we enrich the trait space by incorporating a second dimension, namely the non-economic aversion to immigration.

This paper continues the previous work in Solano (2006), where parties' ideology on immigration was treated exogenously. More precisely, parties were committed to fixed levels of immigration and competed a la Downs on the progressivity of the tax scheme in order to win the elections. Only the non-economic effects of immigration were considered and it was assumed that all workers with the same skill shared the same attitudes toward immigration. This paper relaxes the previous assumptions by incorporating a competitive labor market and assuming heterogeneity of attitudes towards immigration among the workers with the same skill. The cost to pay is the absence of a closed form solution, and we need to rely on numerical simulations to find political equilibria.

At equilibrium the two parties, labelled $L$ and $R$, form along the immigration issue, combining skilled and unskilled workers among their constituencies. In contrast to the Downsian approach, we find that parties differentiate their proposals, and the optimal level of immigration for the median voter lies always in-between parties' proposals.

As immigration control policies become more effective, the more antiimmigration party, party $R$, with a constituency of mainly unskilled workers, slightly increases its probability of winning. A more efficacious immigration control policy leads both parties to propose a lower level of immigration in equilibrium. However, both parties focus on obtaining more votes from their majority group of voters (i.e. party $R$ try to get more votes from unskilled workers and party $L$ try to get more votes from skilled workers), and parties' constituencies become more homogeneous. However, as the efficacy of the immigration policy increases, party $R$ gains more votes from unskilled workers than party $L$ does from skilled workers. This result has a clear implication: more anti-immigration parties will tend to improve the efficacy of the immigration control policy in order to increase their probability of winning the election, generating a higher support for tighter immigration policies.

Regarding the sensitivity to the social cost of immigration, we find that a uniform increase makes both parties to propose a tighter immigration policy. 
This is because skilled and unskilled workers' preferences on immigration become more similar as non-economic effects become more important. Interestingly, the probability of victory of party $L$ follows an inverted U-shaped pattern with respect to the social cost of immigration, increasing for low costs and decreasing for high costs.

Next, we analyze the equilibrium as skilled and unskilled workers increase their differences on the non-economic aspect of immigration. We observe a convergence in parties' proposals. Two effects explain this result. The composition of the voters supporting each party becomes more homogeneous. Then, ceteris paribus, the average utility of the constituency of each party increases. Since parties face a trade off between winning the election and proposing the policy that maximizes their constituency's utility, they are willing to trade-off some of this newly gained utility for a higher probability of winning. Thus, parties' policies tend to converge, with party $L$ announcing a lower level of immigration and party $R$ announcing a higher level of immigration. Nevertheless, an increase on the polarization of the non-economic effect of immigration favors the party with a higher share of the most numerous group (unskilled workers) among its constituency (that is, party $R$ ). Therefore, the probability of victory of party $L$ falls as the two groups of voters move apart on their non-economic views of immigration.

The rest of the paper is organized as follows. Section 2 describes the economic model. In section 3 we derive voters' preferences on immigration policy, present the political competition model, and define the concept of EPWE. In section 4 we specify and calibrate the model. Section 5 presents the main results. We use numerical simulations to compute political equilibria and run comparative statists. Section 6 concludes.

\section{The Economic Model}

\subsection{Natives and Immigrants}

Consider a country with a continuum of natives of mass $n>1$. Natives have direct preferences over consumption $(x)$ and the number of immigrants who reside in the country at a certain time $(m)$. Immigration has a direct effect on the utility of natives that must be understood in a broad sense as any disutility derived from social conflict, xenophobia or native's perception of a link between immigration and insecurity. The key feature of this effect is its independence of any economic impact of immigration. We assume this social impact to be increasing, at a decreasing rate, in the number of immigrants. 
Formally, we take the utility of a native to be

$$
V(x, m)=x-\gamma m^{2},
$$

where $\gamma>0$ measures a native's sensitivity towards the social impact of immigration.

Natives inelastically provide one unit of labor, but differ in the efficiency units that they are capable of delivering in one unit of time. Let $e$ be the endowment of effective units of labor. Hence, a native is characterized by a vector $(\gamma, e)$, with $\gamma \in \Gamma$ and $e \in \Sigma$.

There are two types of labor, skilled and unskilled, labeled by $h=s, u$, respectively. Type- $h$ workers are distributed according to the joint distribution $F^{h}(\gamma, e)$. Let $F_{\gamma}^{h}(e)$ be the marginal distribution of labor ability among type- $h$ workers, with mean $\bar{e}_{h}=\int_{\Sigma} d F_{\gamma}^{h}(e)$ and median $e_{h}^{m}=\left[F_{\gamma}^{h}\right]^{-1}(1 / 2)$. Without loss of generality, we assume that $\bar{e}_{s}>\bar{e}_{u}$. Also, let $F_{e}^{h}(\gamma)$ denote the marginal distribution of the sensitivity towards immigration among type $-h$ workers, with mean $\bar{\gamma}_{h}=\int_{\Gamma} d F_{e}^{h}(\gamma)$ and median $\gamma_{h}^{m}=\left[F_{e}^{h}\right]^{-1}(1 / 2)$. Finally, normalize the mass of skilled workers to one, so that we can express the mass of unskilled workers by $\eta=n-1$.

In addition to natives, there is a mass $m$ of immigrants in the country. Because we focus on mass migrations, we take all immigrants to be unskilled workers and assume for simplicity that they share the same distribution of effective units as native unskilled workers.

Let $w_{u}$ and $w_{s}$ denote the salaries per efficiency unit of labor. A worker endowed with $e_{h}$ efficiency units obtains an income $y\left(e_{h}\right)=e_{h} w_{h}, h=u, s$.

\subsection{Production and Labor Market Equilibrium}

There is a single consumption good produced from efficiency units of unskilled $(u)$ and skilled $(s)$ labor according to the Cobb-Douglas production function

$$
G(u, s)=u^{\alpha} s^{1-\alpha}, \quad \text { with } \alpha \in(0,1) .
$$

Normalize the price of the output to one. Competition in the labor market implies that inputs are paid their marginal productivity. Letting $\mu=\eta \bar{e}_{u} / \bar{e}_{s}$ be the fraction of unskilled over skilled efficiency units of labor, we have

$$
\begin{aligned}
& w_{u}(\mu)=g^{\prime}(\mu)=\alpha \mu^{\alpha-1} \text { and } \\
& w_{s}(\mu)=g(\mu)-g^{\prime}(\mu) \mu=(1-\alpha) \mu^{\alpha},
\end{aligned}
$$

where $g(\mu)=\mu^{\alpha}$ is the output per efficiency unit of skilled labor. 
Notice that if the amount of unskilled labor compared to its relative participation on production is large enough, i.e. $\mu>\frac{\alpha}{1-\alpha}$, then there exists a skill premium, that is $w_{s}(\mu)>w_{u}(\mu)$.

Workers' income can be written as

$$
\begin{aligned}
& y\left(e_{u}\right)=w_{u}(\mu) e_{u}=\alpha \mu^{\alpha-1} e_{u}, \text { and } \\
& y\left(e_{s}\right)=w_{s}(\mu) e_{s}=(1-\alpha) \mu^{\alpha} e_{s},
\end{aligned}
$$

depending on the type of labor they hold.

\subsection{The Economic Effects of Immigration}

Immigrants alter the proportion of unskilled over skilled efficiency units of labor, that is $\mu$, affecting wages. Since immigrants are all unskilled and follow the same distribution of ability than unskilled natives, a mass $m$ of immigrants provides $m \bar{e}_{u}$ efficiency units of unskilled labor. Hence,

$$
\mu(m)=\frac{(m+\eta) \bar{e}_{u}}{\bar{e}_{s}} .
$$

From (2) and (4), and abusing notation, we obtain

$$
\begin{aligned}
& w_{u}(m)=\alpha \mu(m)^{\alpha-1}, \\
& w_{s}(m)=(1-\alpha) \mu(m)^{\alpha} .
\end{aligned}
$$

By the concavity of $g$, we find the standard result that immigration reduces unskilled wage and increases skilled wage (see Borjas and others 1996, 1997):

$$
\begin{aligned}
& \frac{\partial w_{u}}{\partial m}=g^{\prime \prime}(\mu) \frac{\bar{e}_{u}}{\bar{e}_{s}} \leq 0 \\
& \frac{\partial w_{s}}{\partial m}=-g^{\prime \prime}(\mu) \mu \frac{\bar{e}_{u}}{\bar{e}_{s}}=-\mu \frac{\partial w_{u}}{\partial m} \geq 0 .
\end{aligned}
$$

Nevertheless, immigration is beneficial for the economy. Letting total or national income be the sum of unskilled and skilled workers income,

$$
y_{N}(m)=(m+\eta) w_{u}(m) \bar{e}_{u}+w_{s}(m) \bar{e}_{s},
$$

immigration increases total income, although at a decreasing rate: ${ }^{1}$

$$
y_{N}^{\prime}(m)=w_{u}(m) \bar{e}_{u}>0 \text {, and } y_{N}^{\prime \prime}(m)=w_{u}^{\prime}(m) \bar{e}_{u}<0 .
$$

\footnotetext{
${ }^{1}$ By the Cobb Douglas specification, workers' income is a fraction of the domestic
} 


\subsection{Immigration Policy}

Immigration policy aims at maintaining a certain level of immigration. Controlling potential entrants is costly. Thus, immigration policy can be equivalently characterized by the amount of resources devoted to control the flow of immigrants. Formally, define $E(m)$ as the expenditure necessary to keep immigration at level $m$, with $E^{\prime}(m)<0$ and $E^{\prime \prime}(m)>0$. That is, a tighter policy requires a higher expenditure, and the cost increases at an increasing rate. Let $\bar{m}$ be the level of immigration under an open borders policy (that is, $E(\bar{m})=0$ ) and assume that it is unfeasible to completely stem the inflow of immigrants (that is, $E(0)=\infty$ ), reflecting the natural impossibility of a country to perfectly seal its borders.

The government finances immigration policy with a proportional tax $t$ imposed on income. A balanced budget constraint implies

$$
E(m)=t y_{N}(m)
$$

Since immigration increases total income and relaxing border control reduces government expenditure, the tax rate needed to finance immigration control is a decreasing function of the immigration level allowed to enter the country,

$$
t(m)=\frac{E(m)}{y_{N}(m)} \text { and } t^{\prime}(m)=\frac{E^{\prime}(m) y_{N}(m)-y_{N}^{\prime}(m) E(m)}{y_{N}(m)^{2}}<0 .
$$

Total income sets a lower bound $\underline{m}$ on immigration control, reflecting the mass of immigrants when all resources are spent on immigration control $E(\underline{m})=y_{N}(\underline{m}){ }^{2}$ Therefore, we obtain the range of feasible immigration policies to be the interval $[\underline{m}, \bar{m}]$.

income, and so $y_{N}(m)=\frac{\bar{e}_{s}}{1-\alpha} w_{s}(m)$. From $(5), w_{s}(m)=\frac{1-\alpha}{\alpha} \mu(m) w_{u}(m)$. Therefore, $y_{N}(m)=\frac{\bar{e}_{s}}{\alpha} \mu(m) w_{s}(m)$. Differentiating with respect to $m$, and after symplifying,

$$
y_{N}^{\prime}(m)=w_{u}(m) \bar{e}_{u}>0 .
$$

Using (6),

$$
y_{N}^{\prime \prime}(m)=w_{u}^{\prime}(m) \bar{e}_{u}<0 .
$$

\footnotetext{
${ }^{2}$ Because $y_{N}(m)-E(m)$ is a continuous, strictly increasing function with $y_{N}(0)-$ $E(0)=-\infty$ and $y_{N}(\bar{m})-E(\bar{m})=y_{N}(\bar{m})>0$, there exists a unique $\underline{m}>0$ such that $y_{N}(\underline{m})=E(\underline{m})$.
} 


\section{The Political Model: Wittman Equilibria with Endogenous Parties}

\subsection{Natives' Preferences on Immigration}

Substituting the economic effects of immigration (5) into the utility function (1), we obtain the preferences over immigration policies of a worker of type $\left(\gamma, e_{h}\right)$ as represented by the utility function:

$$
v_{h}\left(m ; \gamma, e_{h}\right)=\left(1-\frac{E(m)}{y_{N}(m)}\right) w_{h}(m) e_{h}-\gamma m^{2} .
$$

It follows from the Kunh-Tucker conditions that ideal immigration policies only depend on the ratio between the sensitivity to the social cost of immigration and the level of ability, $m_{h}^{*}\left(\gamma / e_{h}\right)$, as Proposition 1 shows. Furthermore, utility is strictly increasing for natives with a very low $\frac{\gamma}{e_{h}}$, strictly decreasing for natives with a very high $\frac{\gamma}{e_{h}}$, and single-peaked with an interior maximum for the rest.

Proposition 1 The ideal immigration policy for a worker of type $\left(\gamma, e_{h}\right)$ is a function of her ratio $\gamma / e_{h}$. Furthermore, there exist values $\beta_{h}$ and $\zeta_{h}$, with $\beta_{h} \leq \zeta_{h}$, such that

$$
m_{h}^{*}\left(\gamma / e_{h}\right)= \begin{cases}\bar{m} & \text { if } \gamma / e_{h} \leq \beta_{h} \\ \tilde{m}\left(\frac{\gamma}{e_{h}}\right) \in(\underline{m}, \bar{m}) & \text { if } \gamma / e_{h} \in\left(\beta_{h}, \zeta_{h}\right) \\ \underline{m} & \text { if } \gamma / e_{h} \geq \zeta_{h}\end{cases}
$$

where $\tilde{m}\left(\gamma / e_{h}\right)$ is implicitly defined as the unique solution of

$$
\frac{\gamma}{e_{h}}=\frac{\left[-t^{\prime}(m)-(1-t(m)) \frac{k_{h}}{\mu(m)}\right] w_{h}(m)}{2 m} \text {, with } k_{u}=1-\alpha \text { and } k_{s}=-\alpha \text {. }
$$

Proof: See the Appendix.

Unskilled and skilled workers' optimal policies are depicted in figures 2 and 3, showing that (i) as the ratio $\frac{\gamma}{e}$ increases, workers prefer less immigrants; (ii) workers with a sufficiently large $\frac{\gamma}{e}$ prefer the lower bound level of immigration; and (iii) workers with a sufficiently small $\frac{\gamma}{e}$ prefer the upper bound level of immigration. 


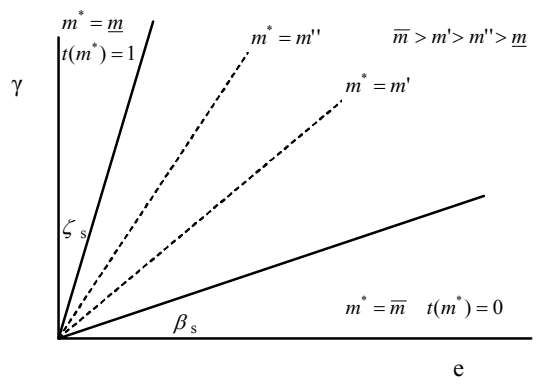

Figure 2. Skilled workers' optimal immigration level

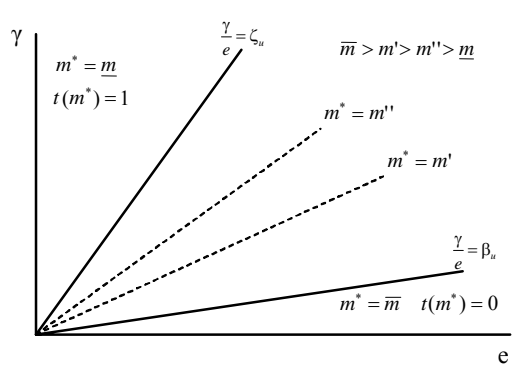

Figure 3. Unskilled workers' optimal immigration level

Secondly, among each group of workers (skilled and unskilled), the optimal level of immigration is negatively correlated with the sensitivity towards immigration and positively correlated with ability.

Proposition 2 Among each group of workers, skilled and unskilled,

i) keeping ability constant, the higher the sensitivity to the social cost of immigration the lower the optimal level of immigration, and

ii) keeping the sensitivity to the social cost of immigration constant, the higher the ability the higher the optimal level of immigration.

Proof: See the Appendix.

Finally, controlling for their characteristics, unskilled workers prefer a lower optimal level of immigration than skilled workers.

Proposition 3 For a given ratio $\gamma / e$, unskilled workers have a lower or equal optimal immigration level than skilled workers. That is, for any $\gamma / e$, $m_{u}^{*}(\gamma / e) \leq m_{s}^{*}(\gamma / e)$

Proof: See the Appendix.

In this society, the median policy is the policy preferred by natives with the median value of $\frac{\gamma}{e}$, which, generically, does not coincide neither with the median unskilled worker, nor with the median skilled worker. In fact, if immigration policy were determined by the median voter, the resulting level of immigration would be, in general, lower than the optimal policy for the median skilled worker and higher than the optimal policy for the median 
unskilled worker. ${ }^{3}$ However, describing the political process as a competition between parties with preferences over the political issues (that is, with ideology) is more appropriate than resorting to the median voter and provides a richer framework of analysis. We choose to define the equilibrium policy as the outcome of an Endogenous Party Wittman Equilibrium (EPWE), proposed by Roemer (2001) as an extension of the Wittman equilibrium in which parties' preferences are endogenously determined.

\subsection{Wittman Equilibria with Endogenous Parties}

There are two parties (denoted by $L$ and $R$ ) competing under majority rule. Parties simultaneously announce their immigration policies. Natives vote for their preferred policy, but parties face uncertainty about the exact distribution of the electorate. The party with the most votes wins and implements the policy announced during the campaign.

Formally, given a pair of policy announcements $m_{L}$ and $m_{R}$, let $\Omega_{h}\left(m_{L}, m_{R}\right)$ be the set of voters within the labor group $h$ who prefer $m_{L}$ to $m_{R}$. That is:

$$
\Omega_{h}\left(m_{L}, m_{R}\right)=\left\{\left(\gamma, e_{h}\right) \in \Gamma \times \Sigma: v_{h}\left(m_{L} ; \gamma, e_{h}\right) \geq v_{h}\left(m_{R} ; \gamma, e_{h}\right)\right\}
$$

Using (10), and for $m_{L}>m_{R}$, we have

$$
\Omega_{h}\left(m_{L}, m_{R}\right)=\left\{\left(\gamma, e_{h}\right) \in \Gamma \times \Sigma: \frac{\gamma}{e_{h}} \leq \Psi_{h}\left(m_{L}, m_{R}\right)\right\}
$$

where $\Psi_{h}\left(m_{L}, m_{R}\right)=\frac{\left(1-t\left(m_{L}\right)\right) w_{h}\left(m_{L}\right)-\left(1-t\left(m_{R}\right)\right) w_{h}\left(m_{R}\right)}{m_{L}^{2}-m_{R}^{2}}$ represents the dividing voter of type $h$.

Let $\Phi_{h}\left(m_{L}, m_{R}\right)$ be the proportion of type- $h$ natives voting for party $L$, corresponding to the measure of the set $\Omega_{h}\left(m_{L}, m_{R}\right)$. Hence, we can compute

$$
\Phi_{h}\left(m_{L}, m_{R}\right)=\int_{\Omega_{h}\left(m_{L}, m_{R}\right)} \mathrm{d} F^{h}(\gamma, e)=\int_{\Gamma} \int_{\Psi_{h}\left(m_{L}, m_{R}\right)} f^{h}(\gamma, e) \partial e \partial \gamma
$$

We know that skilled workers prefer a higher level of immigration than unskilled workers, since not only they benefit from the complementarity of immigration as a production factor, but also they bear a larger share of the

\footnotetext{
${ }^{3}$ The assumption that the median value of $\frac{\gamma}{e}$ for unskilled workers is larger than that for skilled workers is consistent with the empirical literature on attitudes towards immigration (Myda 2006, Dustman and Preston 2005). It follows then that the optimal level of immigration for the median voter is larger than the optimal immigration level for the median unskilled worker and lower than the optimal immigration level for the median skilled worker.
} 
fiscal cost of immigration control (Proposition 3). Thus, it is not surprising that, for $m_{L}>m_{R}, \Psi_{s}\left(m_{L}, m_{R}\right)>\Psi_{u}\left(m_{L}, m_{R}\right)$ whenever there is at least one unskilled worker with an interior optimal level of immigration. ${ }^{4}$. Nevertheless, party $L$ (proposing a less tight immigration policy) may also receive the support of some unskilled workers. This is also true even when unskilled workers are on average more averse to immigration than skilled workers (see Figure 4).

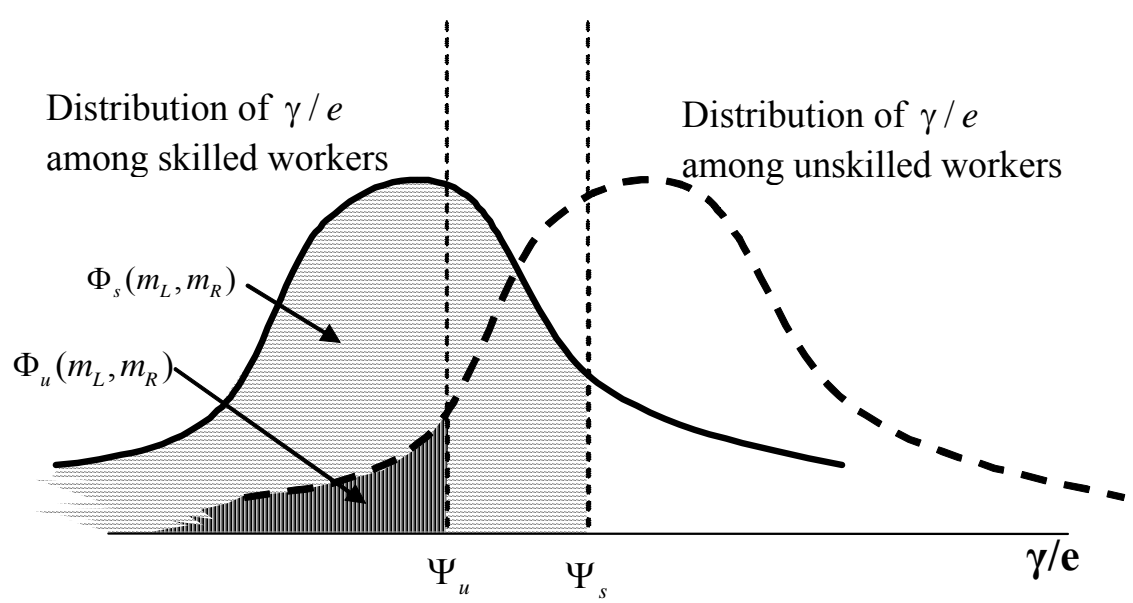

Figure 4. Allocation of votes when unskilled workers are on average more averse to immigration than skilled workers and $m_{L}>m_{R}$.

Therefore, generically, each party will receive votes from both skilled and unskilled workers. Denote by $\Phi^{L}\left(m_{L}, m_{R}\right)$ the total fraction of native voters preferring $m_{L}$ to $m_{R}$. Then,

$$
\Phi^{L}\left(m_{L}, m_{R}\right)=\frac{1}{1+\eta}\left(\Phi_{s}\left(m_{L}, m_{R}\right)+\eta \Phi_{u}\left(m_{L}, m_{R}\right)\right)
$$

\footnotetext{
${ }^{4}$ For $m_{L}>m_{R}, \Psi_{s}\left(m_{L}, m_{R}\right)>\Psi_{u}\left(m_{L}, m_{R}\right)$ if and only if $\left(1-t\left(m_{L}\right)\right) w_{s}\left(m_{L}\right)-\left(1-t\left(m_{R}\right)\right) w_{s}\left(m_{R}\right)>\left(1-t\left(m_{L}\right)\right) w_{u}\left(m_{L}\right)-\left(1-t\left(m_{R}\right)\right) w_{u}\left(m_{R}\right)$.
}

Since $w_{s}(m)=\frac{1-\alpha}{\alpha} \mu(m) w_{u}(m)(2)$,

$$
\left(\frac{1-\alpha}{\alpha} \mu\left(m_{L}\right)-1\right)\left(1-t\left(m_{L}\right)\right) w_{u}\left(m_{L}\right)-\left(\frac{1-\alpha}{\alpha} \mu\left(m_{R}\right)-1\right)\left(1-t\left(m_{R}\right)\right) w_{u}\left(m_{R}\right)>0,
$$

which is satisfied whenever $(1-t(m)) w_{u}(m)$ is an increasing function of $m$, a necessary condition for having at least an unskilled worker with an interior optimal level of immigration $m \in(\underline{m}, \bar{m})$. 
Parties face electoral uncertainty, in the sense that they know the pool of their supporters but can only forecast the share of the vote they will receive with a margin of error $\Delta$. Formally, we follow the "error-distribution model" presented in Roemer (2001, p.45). Let parties $L$ and $R$ propose $m_{R}$ and $m_{L}$, respectively. Then, the proportion of votes that party $L$ expects to receive is a random variable uniformly distributed on the interval $\left(\Phi^{L}\left(m_{L}, m_{R}\right)-\Delta, \Phi^{L}\left(m_{L}, m_{R}\right)+\Delta\right)$, for some $\Delta>0$. It follows that the probability that party $L$ defeats party $R$ is given by

$$
p\left(m_{L}, m_{R}\right)=\left\{\begin{array}{ccc}
0 & \text { if } & \Phi^{L}\left(m_{L}, m_{R}\right)+\Delta \leq 1 / 2 \\
\frac{\Phi^{L}\left(m_{L}, m_{R}\right)+\Delta-1 / 2}{2 \Delta} & & \text { otherwise } \\
1 & \text { if } & \Phi^{L}\left(m_{L}, m_{R}\right)-\Delta \geq 1 / 2 .
\end{array}\right.
$$

And party $R$ defeats party $L$ with probability $1-p\left(m_{L}, m_{R}\right)$.

Parties have policy preferences representing the average utility of their members (Wittman, 1973). Constituents of party $L$ are denoted by the sets of voters $\Omega_{u}^{L}$ and $\Omega_{s}^{L}$, and constituents of party $R$ are denoted by the sets of voters $\Omega_{u}^{R}$ and $\Omega_{s}^{R}$. Thus, the average utility function of party $J$ 's constituents for a policy $m$ is given by:

$$
V^{J}(m)=\frac{1}{1+\eta}\left(\eta \int_{\Omega_{u}^{J}} v_{u}(m ; \gamma, e) d F^{u}(\gamma, e)+\int_{\Omega_{s}^{J}} v_{s}(m ; \gamma, e) d F^{s}(\gamma, e)\right)
$$

Given a distribution of voter preferences, a political equilibrium provides: $i$ ) a partition of the polity into two parties, labeled by $L$ and $R$ respectively; ii) the platform that each party proposes; and iii) the expected vote share of each party.

Both parties simultaneously choose the platform that maximizes their expected utility, given the platform proposed by the other party. At equilibrium, the following two conditions must be satisfied: (1) no party prefers to change its platform given both the platform of the other party and the partition of the polity; and (2) no party's constituent wants to change its membership given the two parties' platforms.

Definition 1 An Endogenous Parties Wittman Equilibrium (EPWE) is a pair of policies $\left(m_{L}^{*}, m_{R}^{*}\right) \in[\underline{m}, \bar{m}]^{2}$ and a partition of the polity $\Omega_{h}^{L}, \Omega_{h}^{R}$ such that:

1. Given $\Omega_{h}^{L}$ and $\Omega_{h}^{R}$,

$$
m_{L}^{*}=\arg \max p\left(m, m_{R}^{*}\right) V^{L}(m)+\left(1-p\left(m, m_{R}^{*}\right)\right) V^{L}\left(m_{R}^{*}\right), \text { and }
$$




$$
m_{R}^{*}=\arg \max p\left(m_{L}^{*}, m\right) V^{R}\left(m_{L}^{*}\right)+\left(1-p\left(m_{L}^{*}, m\right)\right) V^{R}(m) .
$$

2. Given $m_{L}^{*}$ and $m_{R}^{*}$,

$$
\begin{gathered}
\text { if }(\gamma, e) \in \Omega_{h}^{L} \text {, then } v_{h}\left(m_{L}^{*} ; \gamma, e\right) \geq v_{h}\left(m_{R}^{*} ; \gamma, e\right) \text {, and } \\
\text { if }(\gamma, e) \in \Omega_{h}^{R} \text {, then } v_{h}\left(m_{R}^{*} ; \gamma, e\right) \geq v_{h}\left(m_{L}^{*} ; \gamma, e\right) \text {. }
\end{gathered}
$$

The first-order conditions for the maximization problems (13) and (14) show the trade off between proposing a policy closer to the interests of each party's constituency and the corresponding decrease in the probability of victory:

$$
\begin{gathered}
{\left[p\left(m_{L}, m_{R}\right) \frac{\partial V^{L}(m)}{\partial m}\right]+\left[\frac{\partial p\left(m, m_{R}\right)}{\partial m}\left(V^{L}(m)-V^{L}\left(m_{R}\right)\right)\right]=0} \\
{\left[\left(1-p\left(m_{L}, m_{R}\right)\right) \frac{\partial V^{R}(m)}{\partial m}\right]+\left[-\frac{\partial p\left(m_{L}, m\right)}{\partial m}\left(V^{R}(m)-V^{R}\left(m_{L}\right)\right)\right]=0}
\end{gathered}
$$

At equilibrium, the constituency of each party is determined endogenously by expressions (15) and (16). From (11), and given the equilibrium policies $m_{L}^{*}>m_{R}^{*}$, the constituency or each party is fully characterized by a pair $\left(\Psi_{u}^{*}, \Psi_{s}^{*}\right)$, so that all type- $h$ voters with $\gamma / e_{h}<\Psi_{h}^{*}$ constitute party $L$, while the rest constitute party $R$.

Therefore, finding an interior equilibrium requires solving the following systems of four equations in the four unknowns $m_{L}, m_{R}, \Psi_{u}$, and $\Psi_{s}$ :

$$
\begin{gathered}
{\left[p\left(m_{L}, m_{R}\right) \frac{\partial V^{L}(m)}{\partial m}\right]+\left[\frac{\partial p\left(m, m_{R}\right)}{\partial m}\left(V^{L}(m)-V^{L}\left(m_{R}\right)\right)\right]=0} \\
{\left[\left(1-p\left(m_{L}, m_{R}\right)\right) \frac{\partial V^{R}(m)}{\partial m}\right]+\left[-\frac{\partial p\left(m_{L}, m\right)}{\partial m}\left(V^{R}(m)-V^{R}\left(m_{L}\right)\right)\right]=0} \\
\Psi_{s}=\Psi_{s}\left(m_{L}, m_{R}\right) \\
\Psi_{u}=\Psi_{u}\left(m_{L}, m_{R}\right)
\end{gathered}
$$

This system is highly non-linear and eludes analytical solutions. In the following sections we develop a computational model and use Mathematica to find equilibria. 


\section{Specification and Calibration}

In this section we calibrate the model to existing empirical evidence and develop a computational model to illustrate our results and to perform comparative static analysis.

The calibration of the model requires $(i)$ specifying an immigration control technology, and (ii) specifying a distribution of ability and sensitivity towards the social impact of immigration for skilled and unskilled workers.

With respect to the immigration control technology we adopt the following functional form:

$$
E(m)=\theta \frac{\bar{m}-m}{m},
$$

where $\theta$ stands for the efficacy of the immigration policy, and $\bar{m}$ is the potential mass of immigrants willing to enter the country or, alternatively, the open-borders mass of migrants. Both a larger $\theta$ and a larger $\bar{m}$ imply a more costly immigration control policy, as higher expenditure is needed to keep a given level of immigration. We consider several values of $\bar{m}$ and $\theta$ during the simulations and run comparative static analysis.

For the calibration of the joint distribution of ability and sensitivity towards immigrants of natives we proceed in steps. First, we take the participation share of unskilled labor in production from U.S. census data for 2002 $(\alpha=0.32)$, and the skill premium $\left(w_{s} / w_{u}=1.8\right)$ from Hui He $(2003) .^{5}$

Second, we assume that $e$ and $\gamma$ are independent and presume that $\gamma$ is uniformly distributed on $\left[0, \gamma_{h}^{\max }\right]$, where the subindex indicates that the distribution may be different for skilled and unskilled workers. We will consider different values of $\gamma_{s}^{\max }$ and $\gamma_{u}^{\max }$ in the simulations.

We obtain the distribution of ability from the distribution of income (see (3)), which we assume to be distributed log-normal. To calibrate the distribution of income for skilled and unskilled workers we use mean (\$55.8) and median (\$41.6) income for skilled workers and mean (\$24.9) and median $(\$ 19.9)$ income for unskilled workers, in thousands of dollars, from the U.S. census data for 2002 (see Table 4 of the Current Population Survey reproduced in Appendix 7.4). ${ }^{6}$

From the labor market equilibrium conditions, wages can be written as a function of the skill premium (see (2)):

\footnotetext{
${ }^{5}$ We compute the skill premium as the ratio between the mean annualized real wage for 2002 (in terms of year 2000 US dollars) for college graduates and high school graduates, as reported in Hui $\mathrm{Hu}$ (2003).

${ }^{6}$ We use all data from the year 2002 to be consistent with Hui He (2003)
} 


$$
\begin{aligned}
& w_{u}=\alpha\left(\frac{\alpha}{1-\alpha} \frac{w_{s}}{w_{u}}\right)^{\alpha-1}=0.36 \\
& w_{s}=(1-\alpha)\left(\frac{\alpha}{1-\alpha} \frac{w_{s}}{w_{u}}\right)^{\alpha}=0.64 .
\end{aligned}
$$

Since efficiency units of labor are proportional to income (from (3)),

$$
\begin{aligned}
& \bar{e}_{u}=\frac{\bar{y}_{u}}{w_{u}}=69.5, \quad e_{u}^{\text {med }}=\frac{y_{u}^{\text {med }}}{w_{u}}=55.5, \\
& \bar{e}_{s}=\frac{\bar{y}_{s}}{w_{s}}=86.5, \quad e_{s}^{\text {med }}=\frac{y_{s}^{\text {med }}}{w_{s}}=64.5 .
\end{aligned}
$$

Finally, we find the fraction of unskilled over skilled workers from (4)

$$
m_{0}+\eta=\frac{\alpha}{1-\alpha} \frac{w_{s}}{w_{u}} \frac{\bar{e}_{s}}{\bar{e}_{u}}=1.055
$$

\section{Results}

We use the model specified in the previous section to calculate the EPWE and perform comparative statics on the cost of the immigration control policy, defined by the parameters $\theta$ and $\bar{m}$, and on the distribution of voters over the sensitivity to the social cost of immigration $\left(\gamma_{\max }\right)$. For that purpose we use as a baseline the following parameters values $\gamma_{h}^{\max }=20, \theta=1$ and $\bar{m}=1$.

\subsection{Changes in $\theta$ and $\bar{m}$}

The parameters $\theta$ and $\bar{m}$ define the cost function of immigration control. Both a larger $\theta$ and a larger $\bar{m}$ imply a more costly immigration control policy. We only report the effects of changes in $\theta$ as changes in $\bar{m}$ result in equivalent findings.

Recall that $\theta$ measures the efficacy of immigration control policy. The higher the value of $\theta$ the less efficacious the immigration control policy. Figure 5 shows the different interior EPWE as $\theta$ varies from 0.6 to 1.6. Figure 5.a shows the equilibrium share of immigration in total population proposed by parties $L$ and $R,\left(m_{L}, m_{R}\right)$, and the expected share of immigrants after the elections (Exp.m). In Figure 5.b we have represented how party $L$ 's winning probability (Prob L) changes with the efficacy of the immigration control policy in equilibrium. 


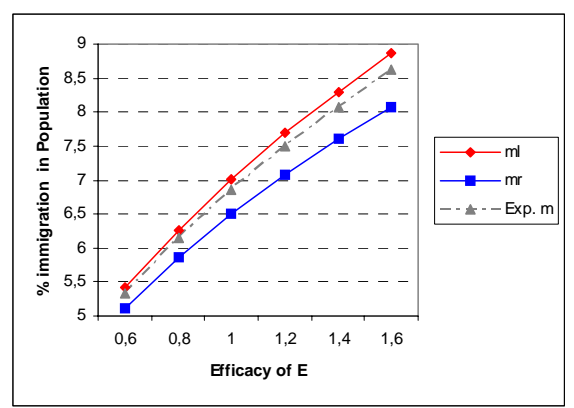

Figure 5.a

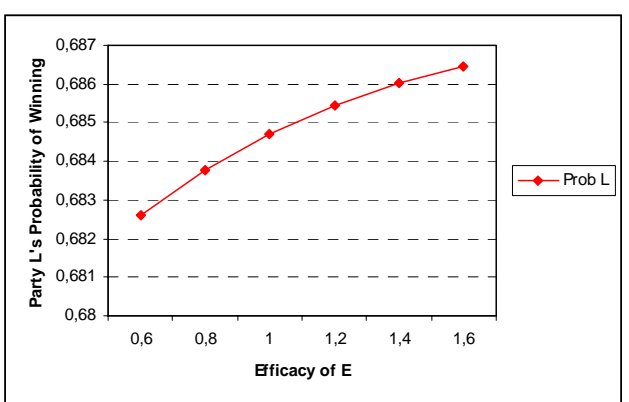

Figure 5.b

In equilibrium, parties offer different levels of immigration, with proposals located to the left and to the right of the median policy. The higher the efficacy of the immigration control policy (that is, the smaller $\theta$ ) the lower the level of immigration proposed by the parties. Technological improvements on immigration control makes all natives (skilled and unskilled workers) prefer less immigration. This effect on voters' preferences explains why party $R^{\prime} s$ winning probability slightly increases, as Figure 5.b shows. Thus, as the technology of immigration control becomes more effective parties converge in proposals on the level of immigration.

Next we look at the composition of the constituency of parties. Table 1 reports the proportion of skilled workers $(\mathrm{S}(\%))$ and unskilled workers $(\mathrm{U}(\%))$ voting for party L in equilibrium. Additionally, it also shows the fraction of skilled workers that prefer an open border policy in equilibrium (Open_S $(\%)$ ).

\begin{tabular}{|c|c|c|c|}
\hline$\theta$ & $\mathbf{S ~ ( \% )}$ & $\mathbf{U}(\%)$ & Open_S (\%) \\
\hline 0,6 & 99,89 & 11,31 & 25,67 \\
\hline 0,8 & 99,80 & 11,44 & 25,98 \\
\hline 1 & 99,68 & 11,58 & 26,29 \\
\hline 1,2 & 99,55 & 11,73 & 26,59 \\
\hline 1,4 & 99,39 & 11,89 & 26,90 \\
\hline 1,6 & 99,23 & 12,06 & 27,20 \\
\hline
\end{tabular}

Table 1: Efficacy and Parties' composition

Consistent with Proposition 3, a majority of skilled workers vote for Party $L$ while a majority unskilled workers vote for party $R$. The proportion of skilled workers voting for party $L$ slightly increases with the efficacy of the immigration policy. However party $L$ loses votes from unskilled workers (the largest group) as immigration control is more effective. Therefore, parties' 
memberships become more homogeneous with the efficacy of the immigration policy, i.e. the higher the efficacy of the immigration policy the larger the proportion of skilled to unskilled workers voting for party $L$ (and correspondingly the larger the proportion of unskilled to skilled workers voting for party $R$ ).

\subsection{Changes in $\gamma_{\max }$}

We take the distribution of $\gamma$ to be the same for skilled and unskilled workers (that is, $\gamma$ is distributed uniformly on $\left[0, \gamma_{\max }\right)$ ), and study equilibria for different values of $\gamma_{\max } \cdot{ }^{7}$ Figure 6 shows interior EPWEs for different values of $\gamma_{\max }$ as it varies from 10 to 70 .

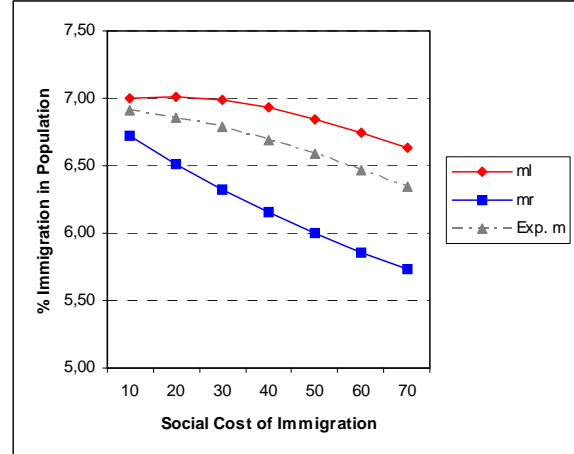

Figure 6.a

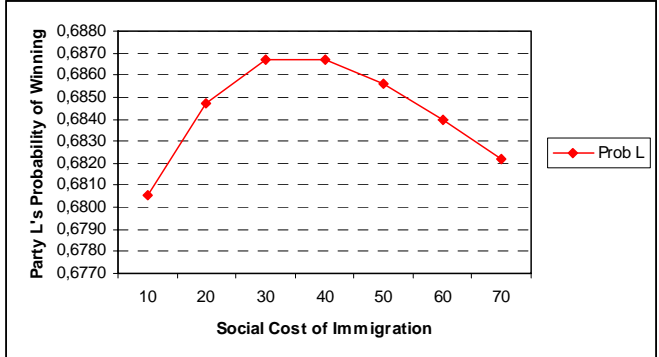

Figure 6.b

We find that parties propose lower levels of immigration as society becomes more sensitive to the social cost of immigration. Interestingly, the effect on the level of immigration proposed by the parties is larger for party $R$ than for party $L$ (Figure 6.a). Therefore, increases on the sensitivity to the social cost of immigration induces a divergence in policy proposals.

Party L's winning probability follows an inverted U-shaped (Figure 6.b). The explanation is provided by the data in Table 2. Given that immigration produces opposite effects on skilled and unskilled workers' wages, societies with a low sensitivity to the social cost of immigration present very differentiated preferences between skilled and unskilled workers, which reflects in the composition of parties' membership. Both divergence in preferences on immigration between skilled and unskilled workers and polarization in parties' memberships fall as the sensitivity of the social cost of immigration becomes

${ }^{7}$ We postpone the study the case of different distributions to the next subsection. 
more relevant. In particular, for very low non-economic effects of immigration, increases in the sensitivity to the social cost of immigration provoke a large shift of unskilled workers' votes towards party $L$, increasing its probability of victory. However, the opposite occurs for high values of the non economic effect of immigration.

\begin{tabular}{|c|c|c|c|}
\hline$\gamma$ max & S (\%) & U (\%) & Open_S (\%) \\
\hline 10 & 99,98 & 11,15 & 47,46 \\
\hline 20 & 99,68 & 11,58 & 26,29 \\
\hline 30 & 98,93 & 12,35 & 17,85 \\
\hline 40 & 97,82 & 13,37 & 13,45 \\
\hline 50 & 96,54 & 14,50 & 10,78 \\
\hline 60 & 95,22 & 15,64 & 8,99 \\
\hline 70 & 93,95 & 16,73 & 7,71 \\
\hline
\end{tabular}

Table 2. Social cost of immigration and parties' composition

\subsection{Changes in $\gamma_{\max }^{u}$ and $\gamma_{\max }^{s}$}

Finally, we analyze interior EPWE for the case in which the sensitivity to the social cost of immigration is different between skilled and unskilled workers. In particular, we are interested in studying the outcome as the two groups diverge on their non-economic aversion to immigration. Following the empirical evidence (see Dustmann and Preston 2005, and Mayda 2006), we assume that the non economic effect of immigration is larger for unskilled workers than for skilled workers.

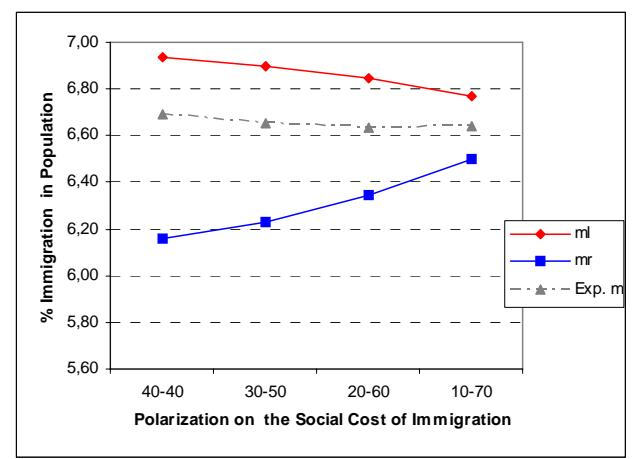

Figure 7.a

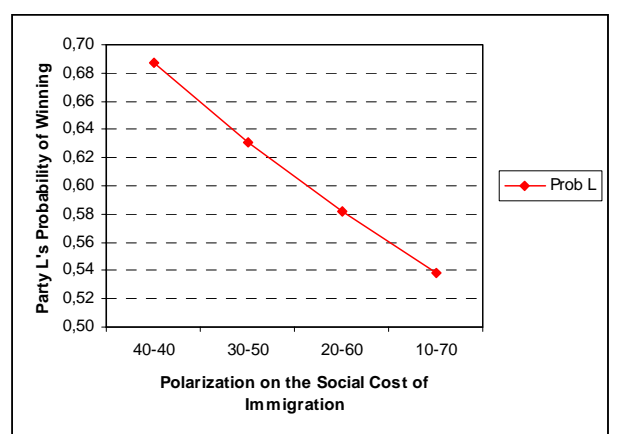

Figure 7.b

Figure 7.a shows that parties' proposals converge as skilled and unskilled workers increase their differences on the non-economic aspect of immigration. 
Divergence on the non economic cost of immigration induces polarization on the preferences over immigration between skilled and unskilled workers. Then, ceteris paribus, the average utility of the constituency of each party increases. Since parties face a trade off between winning the election and maximize their constituency's utility, they are willing to trade-off some of this newly gained utility for a higher probability of winning. Thus, party $L$ announces a lower level of immigration, while party $R$ announces a higher level of immigration in order to increase their winning probabilities.

As the two groups of voters move apart on their non-economic views of immigration, the probability of victory of party $L$ falls (Figure 7.b), favoring the party with a higher share of the most numerous group (unskilled workers) among its constituency (that is, party $R$ ).

\begin{tabular}{|c|c|c|c|}
\hline$\gamma$ max S-U & S (\%) & U (\%) & Open_S (\%) \\
\hline $40-40$ & 97,82 & 13,37 & 13,45 \\
\hline $30-50$ & 99,04 & 10,11 & 17,85 \\
\hline $20-60$ & 99,75 & 7,57 & 26,29 \\
\hline $10-70$ & 99,99 & 5,69 & 47,46 \\
\hline
\end{tabular}

Table 3. Polarization and parties' composition.

Consistent with our previous comments, an increase in polarization increases the divergence of parties' memberships, as represented by their composition. Table 3 shows this result. We also observe that the increase in unskilled workers' votes for party $R$ is larger than the increase in skilled workers' votes for party $L$.

\section{Conclusions}

This paper analyzes the political economy of immigration when the relevant electoral issue is the control of immigration and the relevant immigration policy is the expenditure on border control. Parties are ideological, and their ideologies are endogenously determined at equilibrium. Immigration has economic (via labor market) and non-economic (via social adaptation) effects on natives. In the economic dimension, immigrants compete with unskilled workers and lower the market wage, but complement skilled labor, increasing skilled wage. At equilibrium, parties propose differentiated policies and combine skilled and unskilled workers among their constituencies, with the more anti-immigration party (party $R$ ) holding a majority of unskilled workers. 
We find that, as immigration control technology becomes more efficacious, both parties propose a lower level of immigration. Moreover, political immigration proposals converge and Party $R$, appealing at the most numerous group (unskilled workers), slightly increases its probability of victory. Thus, we would expect that parties focused on anti-immigration policies would invest in improving the efficacy of the immigration control policy.

We also find that, as unskilled workers' non economic attitudes towards immigration are more intense relative to the skilled workers' ones, parties' proposal on immigration converge. In addition, the polarization of attitudes towards immigration increases Party $R^{\prime} s$ probability of victory much more than it does the improve in the immigration control technology mentioned before. Therefore, we may also expect that parties focused on anti-immigration policies have an interest in rising the concern about immigration among unskilled workers.

Finally, in a recent paper, Ortega (2009) compares pure temporary migration and permanent migration in a dynamic political-economy model where both income redistribution and the number of immigrants are chosen by majority vote. We believe that the political competition model designed in the current paper presents a good framework to analyze the decision to extend the franchise to immigrants in a context with endogenous party formation. It would be interesting to explore whether we find what Barbera, Maschler and Shalev (2001) name "voting for your enemy", that is, immigrants (unskilled workers) voting for the party with a constituency formed by a majority of skilled workers. We leave this issue for future research.

\section{References}

[1] Barbera, S., Maschler, M., Shalev, J. (2001) "Voting for voters: A Model of Electoral Evolution." Games and Economic Behavior. 37(1): 40-78

[2] Bauer T., Lofstrom M., Zimmermann K.F. (2000) "Policy, Assimilation of Immigrants and Natives' Sentiments towards Immigrants: Evidence from 12 OECD-Countries." Swedish Economic Policy Review 7: 11-53

[3] Borjas G.J., Freeman R., Katz L.F. (1996) "Searching for the Effects of Immigration on the Labor Market." American Economic Review 86 (2): $247-251$

[4] Borjas G.J., Freeman R., Katz L.F. (1997) "How Much Do Immigration and Trade Affect Labor Market Outcomes?" Brookings Papers on Economic Activity 1: 1-90 
[5] De Donder P.H., Hindriks J. (2006) "Equilibrium Social Insurance with Policy-Motivated Parties." European Journal of Political Economy 23(3): 624-640

[6] Dustmann C., Preston I. (2005) "Is immigration Good or Bad for the economy? Analysis of Attitudinal Responses." Research in Labour Economics 24:3-34

[7] Lee W., Roemer J.E. (2005) "The Rise and Fall of Unionised Labour Markets: A Political Economy Approach." The Economic Journal 115 (2): $28-67$

[8] Mayda A.M. (2006) "Who is Against Immigration? A Cross-Country Investigation of Individual Attitudes toward Immigrants." The Review of Economics and Statistics 88(3): 510-530.

[9] Ortega F.(2009) "Immigration, Citizenship, and the Size of Government." Mimeo.

[10] Ortuño-Ortín I., Roemer J.E. (2000) "Endogenous Formation and the Effect of Income Distribution on Policy." IVIE Working Papers 2000-06.

[11] Roemer J.E. (2001) Political Competition. Theory and Applications. Harvard University Press

[12] Scheve K.F., Slaughter M.J. (2001) "Labor Market Competition and Individual Preferences over Immigration Policy." The Review of Economics and Statistics 83(1): 133-145

[13] Solano A. (2006) "Does Illegal Immigration Empower Rightist Parties?" Journal of Population Economics 19: 649-670.

[14] Wittman D. (1973) "Parties as Utility Maximizers." American Political Science Review. 67: 490-498 


\section{Appendix.}

\subsection{Proof of Proposition 1.}

An unskilled worker characterized by a pair $(\gamma, e)$ solves the following maximization problem:

$$
\begin{gathered}
\underset{m}{\operatorname{Max}}\left(1-\frac{E(m)}{y_{N}(m)}\right) w_{h}(m) e-\gamma m^{2} \\
\text { s.t. } m \leq \bar{m} \\
t(m) \leq 1
\end{gathered}
$$

The Lagrangian function corresponding to this maximization problem is the following:

$$
L\left(m, \lambda_{1}, \lambda_{2}\right)=\left(1-\frac{E(m)}{y_{N}(m)}\right) w_{h}(m) e-\gamma m^{2}+\lambda_{1}(\bar{m}-m)+\lambda_{2}(1-t(m))
$$

Let's first analyze the corner solutions. There are only two possible corner solutions that are i) $m^{*}=\bar{m}, t\left(m^{*}\right)=0$ and ii) $m^{*}=\underline{m}, t\left(m^{*}\right)=1$.

In the case of solution i) we have the following FOC:

$$
-\frac{E^{\prime}(\bar{m})}{y_{N}(\bar{m})} w_{h}(\bar{m}) e+w_{h}^{\prime}(\bar{m}) e-2 \gamma \bar{m}-\lambda_{1} \geq 0
$$

Using the following equality $w_{h}^{\prime}(m)=-\frac{k_{h}}{\mu(m)} w_{h}(m)$ for all $m$, we have that the FOC is given by:

$$
\left(-\frac{E^{\prime}(\bar{m})}{y_{N}(\bar{m})}-\frac{k_{h}}{\mu(\bar{m})}\right) w_{h}(\bar{m}) e-2 \gamma \bar{m}-\lambda_{1} \geq 0
$$

Assume $\lambda_{1}=0$, then the optimal policy for unskilled workers characterized by a pair $(\gamma, e)$ such that:

$$
\frac{\gamma}{e} \leq \frac{\left(-\frac{E^{\prime}(\bar{m})}{y_{N}(\bar{m})}-\frac{k_{h}}{\mu(\bar{m})}\right)}{2 \bar{m}} w_{u}(\bar{m})
$$

is $m^{*}=\bar{m}$, and $t\left(m^{*}\right)=0$. Let's define

$$
\beta_{h}=\frac{\left(-\frac{E^{\prime}(\bar{m})}{y_{N}(\bar{m})}-\frac{k_{h}}{\mu(\bar{m})}\right)}{2 \bar{m}} w_{h}(\bar{m}) .
$$

Is $\beta_{h}$ positive? i.e. are there unskilled workers that have this optimal policy? We find that for a sufficiently large efficacy of the immigration policy relative to the maximum level of immigration, $\bar{m}$, there are workers that 
have this optimal policy. In particular, if $-E^{\prime}(\bar{m})>\frac{k_{h}}{\mu(\bar{m})} y_{N}(\bar{m})$, there exist unskilled workers that prefer the maximum level of immigration but no to have any income taxation.

Regarding solution ii) we have that $m^{*}=\underline{m}, t\left(m^{*}\right)=1$ is a maximum if for all $m>\underline{m}$ we have that:

$$
\left(1-\frac{E(m)}{y_{N}(m)}\right) w_{h}(m) e-\gamma m^{2} \leq-\gamma \underline{m}^{2}
$$

The optimal policy for workers characterized by a pair $(\gamma, e)$ such that:

$$
\frac{\gamma}{e} \geq \underset{m}{\arg \max }\left\{\frac{1-\frac{E(m)}{y_{N}(m)}}{m^{2}-\underline{m}^{2}} w_{h}(m)\right\}
$$

is $m^{*}=\underline{m}$, and $t\left(m^{*}\right)=1$. Let's define:

$$
\zeta_{h}=\underset{m}{\arg \max }\left\{\frac{1-\frac{E(m)}{y_{N}(m)}}{m^{2}-\underline{m}^{2}} w_{h}(m)\right\}
$$

for all $m>\underline{m}$. Hence, if $\gamma / e \geq \zeta_{h}$, unskilled workers' optimal policy $m^{*}$ is $m^{*}=\underline{m}$, and $t\left(m^{*}\right)=1$

With respect to the interior solutions, that is $m^{*} \in(\underline{m}, \bar{m})$ and $t\left(m^{*}\right)<1$, the FOC is given by the following expression:

$$
-t^{\prime}\left(m^{*}\right) w_{h}\left(m^{*}\right) e-\frac{k_{h}}{\mu\left(m^{*}\right)} w_{h}\left(m^{*}\right) e-2 \gamma m^{*}=0
$$

The optimal policy for unskilled workers characterized by a pair $(\gamma, e)$ such that:

$$
\frac{\gamma}{e}=\frac{\left[-t^{\prime}\left(m^{*}\right)-\frac{k_{h}}{\mu\left(m^{*}\right)}\left(1-t\left(m^{*}\right)\right)\right] w_{h}\left(m^{*}\right)}{2 m^{*}}
$$

is $m^{*} \in(\underline{m}, \bar{m})$ and $t\left(m^{*}\right)<1$. Notice that, by the FOC, $-t^{\prime}\left(m^{*}\right)>$ $\frac{k_{h}}{\mu\left(m^{*}\right)}\left(1-t\left(m^{*}\right)\right)$ to have $m^{*} \in(\underline{m}, \bar{m})$.

The Second Order Condition (SOC) is satisfied if and only if for all $m^{*} \in(\underline{m}, \bar{m}):$

$$
\left(-t^{\prime \prime} w_{h}\left(m^{*}\right)-2 t^{\prime} w_{h}^{\prime}\left(m^{*}\right)+(1-t) w_{h}^{\prime \prime}\left(m^{*}\right)\right) e-2 \gamma \leq 0
$$

Due to $w_{h}^{\prime}\left(m^{*}\right)$ and $w_{h}^{\prime \prime}\left(m^{*}\right)$ are different expressions for skilled and unskilled workers, we first prove that SOC is satisfied for unskilled workers and then we do the same for skilled workers. 
Then, $m^{*} \in(\underline{m}, \bar{m})$ maximizes unskilled workers' utility if and only if:

$$
\frac{\gamma}{e} \geq \frac{\left(-t^{\prime \prime}-2 t^{\prime} \frac{(1-\alpha)}{\mu}+(1-t) \frac{(1-\alpha)(2-\alpha)}{\mu^{2}}\right) w_{u}}{2}
$$

Using the FOC, $m^{*} \in(\underline{m}, \bar{m})$ maximizes unskilled workers' utility iff:

$$
\frac{\left[-t^{\prime}-\frac{(1-\alpha)}{\mu}(1-t)\right] w_{u}}{2 m^{*}} \geq \frac{\left(-t^{\prime \prime}-2 t^{\prime} \frac{(1-\alpha)}{\mu}+(1-t) \frac{(1-\alpha)(2-\alpha)}{\mu^{2}}\right) w_{u}}{2}
$$

We can express $t^{\prime \prime}$ as a function of $t^{\prime}$ that is:

$$
t^{\prime \prime}=A-\frac{2 \alpha}{\mu} \frac{\bar{e}_{u}}{\bar{e}_{s}} t^{\prime}
$$

where $A=\frac{E^{\prime \prime} y_{N}-y_{N}^{\prime \prime} E}{y_{N}^{2}}>0$. Substituting and simplifying $m^{*} \in(\underline{m}, \bar{m})$ maximizes unskilled workers' utility if and only if:

$$
-t^{\prime} \frac{\alpha m}{\mu}\left(2 \frac{\bar{e}_{u}}{\bar{e}_{s}}-1\right)+A m-t^{\prime} B>\frac{(1-\alpha)}{\mu}(1-t) B
$$

where $B=1+\frac{(2-\alpha) m}{\mu}>0$. We know by the FOC that $-t^{\prime}\left(m^{*}\right)>$ $\frac{(1-\alpha)}{\mu\left(m^{*}\right)}\left(1-t\left(m^{*}\right)\right)$ to have $m^{*} \in(\underline{m}, \bar{m})$. Then a sufficient condition for the SOC to be satisfied is that:

$$
\frac{\bar{e}_{u}}{\bar{e}_{s}}>\frac{1}{2}
$$

Using the equivalence between unskilled and skilled workers' wage, i.e. $w_{s}=\frac{1}{\mu} \frac{1-\alpha}{\alpha} w_{u}$, we can express the SOC for skilled workers in terms of unskilled workers' wage. The SOC is satisfied if and only if for all $m^{*} \in(\underline{m}, \bar{m})$ :

$$
\left(-t^{\prime \prime}-2 t^{\prime}(1-\alpha)+(1-\alpha)^{2} \frac{(1-t)}{\mu^{2}}\right) w_{u} e-2 \gamma \leq 0
$$

Then, $m^{*} \in(\underline{m}, \bar{m})$ maximizes skilled workers' utility if and only if:

$$
\frac{\gamma}{e} \geq \frac{\left(-t^{\prime \prime}-2 t^{\prime} \frac{(1-\alpha)}{\mu}+(1-t) \frac{(1-\alpha)^{2}}{\mu}\right) w_{u}}{2}
$$

Using the FOC, $m^{*} \in(\underline{m}, \bar{m})$ maximizes skilled workers' utility if and only if: 


$$
\frac{\left[-t^{\prime}+\frac{\alpha}{\mu}(1-t)\right] w_{u}}{2 m^{*}} \geq \frac{\left(-t^{\prime \prime}-2 t^{\prime} \frac{(1-\alpha)}{\mu}+(1-t) \frac{(1-\alpha)^{2}}{\mu}\right) w_{u}}{2}
$$

Comparing 22 with 23 we obtain that if SOC is satisfied for unskilled workers it is also satisfied for skilled workers.

\subsection{Proof of Proposition 2.}

In the part A of the appendix the workers' utility maximization problem is solved. FOC yields to the following expression:

$$
\left[-t^{\prime}\left(m^{*}\right)-\left(1-t\left(m^{*}\right)\right) \frac{k_{h}}{\mu(m)}\right] w_{h}\left(m^{*}\right) e-2 \gamma m^{*}=0
$$

Therefore, if the object in brackets in the equation above decreases with $m$ we have that the SOC is satisfied. This implies that workers with a larger ratio $\gamma / e$ have an optimal level of immigration smaller than those with a smaller ratio $\gamma / e$. This result proves both i) and ii).

\subsection{Proof of Proposition 3.}

Consider first unskilled and skilled workers that have the same optimal level of immigration $m$ such that $m \in(\underline{m}, \bar{m})$. Let us define the following functions:

$$
\begin{aligned}
& \frac{\gamma}{e_{s}}(m)=\frac{\left[-t^{\prime}(m)+(1-t(m)) \frac{\alpha}{\mu(m)}\right] w_{s}(m)}{2 m} \\
& \frac{\gamma}{e_{u}}(m)=\frac{\left[-t^{\prime}(m)-(1-t(m)) \frac{1-\alpha}{\mu(m)}\right] w_{u}(m)}{2 m}
\end{aligned}
$$

For all $m \in(\underline{m}, \bar{m}), \frac{\gamma}{e_{s}}(m)>\frac{\gamma}{e_{u}}(m)$ if and only if:

$$
\left[-t^{\prime}(m)+(1-t(m)) \frac{\alpha}{\mu(m)}\right] w_{s}(m)>\left[-t^{\prime}(m)-(1-t(m)) \frac{1-\alpha}{\mu(m)}\right] w_{u}(m)
$$

Using $w_{s}=\frac{1-\alpha}{\alpha} \mu w_{u}$ we can rewrite it as:

$$
w_{u}(m)(1-\alpha)(1-t(m))\left[1+\frac{1}{\mu(m)}\right]>-t^{\prime}(m)\left(w_{u}(m)-w_{s}(m)\right)
$$


which is always satisfied for all $m \in(\underline{m}, \bar{m})$. Thus $\frac{\gamma}{e_{s}}(m)>\frac{\gamma}{e_{u}}(m)$ for all $m \in(\underline{m}, \bar{m})$. Since $\frac{\gamma}{e_{i}}(m)$ is decreasing on $m$ for all $m \in(\underline{m}, \bar{m})$ among skilled and unskilled workers with the same $\frac{\gamma}{e}$, unskilled workers have an optimal $m$ lower than the optimal one for skilled workers.

Second, the optimal policy for skilled and unskilled workers is $m=\bar{m}$ iff $\frac{\gamma}{e} \leq \beta_{u}$ and $\frac{\gamma}{e} \leq \beta_{s}$. Then, for all skilled and unskilled workers with the same $\frac{\gamma}{e}$ we have that unskilled workers have an optimal $m$ lower or equal than the optimal one for skilled workers if and only if $\beta_{s}>\beta_{u}$. However, this is true because by comparing the expression for $\beta_{s}$ and $\beta_{u}$ derived in the part $\mathrm{A}$ of the appendix it follows:

$$
\frac{\left(-\frac{E^{\prime}(\bar{m})}{y_{N}(\bar{m})}+\frac{\alpha}{\mu(\bar{m})}\right)}{2 \bar{m}} w_{s}(\bar{m})>\frac{\left(-\frac{E^{\prime}(\bar{m})}{y_{N}(\bar{m})}-\frac{(1-\alpha)}{\mu(\bar{m})}\right)}{2 \bar{m}} w_{u}(\bar{m})
$$

Hence, among all skilled and unskilled workers with the same $\frac{\gamma}{e}$ such that $\beta_{u}<\frac{\gamma}{e} \leq \beta_{s}$ unskilled workers have an optimal $m$ lower than the optimal one for skilled workers. However, among all skilled and unskilled workers with the same $\frac{\gamma}{e}$ such that $\frac{\gamma}{e} \leq \beta_{u}$ unskilled workers have an optimal $m$ equal as the optimal one for skilled workers, i.e. $m=\bar{m}$.

Third, the optimal policy for skilled and unskilled workers is $m=\underline{m}$ if and only if $\frac{\gamma}{e} \geq \zeta_{u}$ and $\frac{\gamma}{e} \geq \zeta_{s}$. Then, all skilled and unskilled workers with the same $\frac{\gamma}{e}$ we have that unskilled workers have an optimal $m$ lower or equal than the optimal one for skilled workers if and only if $\zeta_{s}>\zeta_{u}$. However this is true because of by comparing the expression for $\zeta_{s}$ and $\zeta_{u}$ derived in the part $\mathrm{A}$ of the appendix for all $m>\underline{m}$ it follows:

$$
\underset{m}{\arg \max }\left\{\frac{1-\frac{E(m)}{y_{N}(m)}}{m^{2}-\underline{m}^{2}} w_{s}(m)\right\}>\arg \max \left\{\frac{1-\frac{E(m)}{y_{N}(m)}}{m^{2}-\underline{m}^{2}} w_{u}(m)\right\}
$$

However it is true for all $m>\underline{m}$ since:

$$
\frac{1-\frac{E(m)}{y_{N}(m)}}{m^{2}-\underline{m}^{2}} w_{s}(m)>\frac{1-\frac{E(m)}{y_{N}(m)}}{m^{2}-\underline{m}^{2}} w_{u}(m)
$$

Hence, among all skilled and unskilled workers with the same $\frac{\gamma}{e}$ such that $\zeta_{u} \leq \frac{\gamma}{e}<\zeta_{s}$ unskilled workers have an optimal $m$ lower than the optimal one for skilled workers. However, among all skilled and unskilled workers with the same $\frac{\gamma}{e}$ such that $\frac{\gamma}{e} \geq \zeta_{s}$ unskilled workers have an optimal $m$ equal as the optimal one for skilled workers, i.e. $m=\underline{m}$. 


\subsection{Distribution of income among skilled and unskilled workers}

Table 4. Income in 2000-2003 by Educational Attainment for People 18 Years Old and Over

\begin{tabular}{|c|c|c|c|c|c|c|}
\hline & \multicolumn{2}{|l|}{ Both Sexes } & \multicolumn{2}{|c|}{ UNSKILLED } & \multicolumn{2}{|c|}{ SKILLED } \\
\hline & 18 Years and Over & $\begin{array}{l}\text { UnskillesI } \\
\text { Skilled }\end{array}$ & $\begin{array}{c}\text { Graduate, } \\
\text { including } \\
\text { GED }\end{array}$ & $\begin{array}{l}\text { Part. } \\
\text { prod. }\end{array}$ & $\begin{array}{l}\text { Part. } \\
\text { prod. }\end{array}$ & $\begin{array}{l}\text { Bachelor's } \\
\text { or more }\end{array}$ \\
\hline 2000 & \begin{tabular}{|c} 
All Workers \\
With Income \\
... Median Income \\
Mean Income
\end{tabular} & 1,2951665 & $\begin{array}{r}62.326 \\
\$ 19.493 \\
\$ 24.030\end{array}$ & 0,3257687 & 0,6742313 & $\begin{array}{r}48.122 \\
\$ 41.133 \\
\$ 55.559\end{array}$ \\
\hline 2001 & $\begin{array}{l}\text { All Workers } \\
\text { With Income } \\
\text {... Median Income } \\
\text {... Mean Income } \\
\text { Mean }\end{array}$ & 1,252175 & $\begin{array}{r}62.034 \\
\$ 19.900 \\
\$ 24.885\end{array}$ & 0,3237843 & 0,6762157 & $\begin{array}{r}49.541 \\
\$ 41.648 \\
\$ 56.376\end{array}$ \\
\hline 2002 & $\begin{array}{l}\text { All Workers } \\
\text { With Income } \\
\text {... Median Income } \\
\text { Mean Income }\end{array}$ & 1,2260252 & $\begin{array}{r}62.363 \\
\$ 19.946 \\
\$ 24.989\end{array}$ & 0,3199126 & 0,6800874 & $\begin{array}{r}50.866 \\
\$ 41.620 \\
\$ 55.846\end{array}$ \\
\hline 2003 & $\begin{array}{l}\text { All Workers } \\
\text { With Income } \\
\text {... Median Income } \\
\text { Mean Income }\end{array}$ & 1,2001951 & $\begin{array}{r}62.751 \\
\$ 20.431 \\
\$ 25.487\end{array}$ & 0,3163778 & 0,6836222 & $\begin{array}{r}52.284 \\
\$ 42.069 \\
\$ 56.596\end{array}$ \\
\hline $2000-2003$ & $\begin{array}{l}\text { All Workers } \\
\text { With Income } \\
\text {... Median Income } \\
\text { Mean Income }\end{array}$ & 1,2433904 & $\begin{array}{r}62.369 \\
\$ 19.943 \\
\$ 24.848\end{array}$ & 0,3214608 & 0,6785392 & $\begin{array}{r}50.203 \\
\$ 41.618 \\
\$ 56.094\end{array}$ \\
\hline
\end{tabular}

Source: U.S. Census Bureau, Current Population Survey Internet Release date: March 2005 